\title{
Regional Variations in Health Disparities
}

\section{: A Cross-Regional Comparison of Self-Rated Health Determinants in Reform-era China}

\author{
Soyoung Kwon \\ Texas A \& M University, Kingsville, 700 University Blvd, MSC 177, TX 78363, U.S.A \\ Soyoung.kwon@tamuk.edu
}

\begin{abstract} health disparities in reform-era China.

Sociology

\section{SUBJECT CLASSIFICATION}

It is well documented that higher socioeconomic status is associated with favorable health status. Given regional variations in the pace and consequence of economic reform in China, this relationship may differ cross-regionally. Building upon the theoretical notion about distinct stratification system under state-socialism versus market economy, as well as the fundamental causes of health disparities, this study compares the association of education and cadre status with selfrated health across geographical regions (e.g., provinces) in reform-era China. Analyses of data pooled from the 19912000 China Health and Nutrition Survey reveal that the association between education and self-rated health is stronger in a more marketized region. Health benefits associated with a cadre status tend to decline in a more marketized region, which however fails to reach a statistical significance. The findings highlight the role regional contexts play in shaping

\section{Key Words: China, Education, Cadre status, Self-rated health, Regions, Economic reform Academic Discipline And Sub-Disciplines}

Medical sociology

\section{TYPE (METHOD/APPROACH)}

\author{
Quntitative analysis
}

\section{INTRODUCTION}

A large body of literature have documented that socioeconomic status (SES) is an important predictor of health. Individuals with lower education or lower income tend to have better health status (Ross \& Wu, 1995; Williams \& Collins, 1995). This relationship spans across time and place, but increased recognition is also being given to the importance of contexts at various scales of geographical coverage, including neighborhood, local, regional, and national context. Accordingly, a more nuance question is under what conditions socioeconomic status matters for health. Scholars increasingly call for a comparative approach to health disparities, illuminating that social determinants of health are context-specific (e.g., Beckfield \&Krieger, 2009; Dow \& Rehkopf, 2010; Kumanyika, 2012). For instance, considering that the United States and Iceland represents two opposite welfare-state regimes - that is, a liberal welfare state in the U.S and a social-democratic welfare state in Iceland, Olafdottir (2007) compares health disparities between the two countries. This cross-national comparison illustrates the role of institutional arrangements (i.e., social welfare policy, levels of inequality) in shaping the relationship between stratification and health disparities (Olafdottir, 2007). Comparisons of health disparities suggest that the nature and strength of the associations between SES and health varies by countries because of different sociopolitical and historical contexts.

While the association between social status and health addresses how an individual gains (un) favorable health based on individual characteristics, a comparison study that allows for considering institutional and other broader contextual sources of inequality is expected to further illuminate the inequality structure. One can also gain such insight when considering regional heterogeneity within a country. An extant comparison study has been exclusively conducted at the national level especially in Western countries, whereas very few studies have considered the regional context that modifies health disparities within a non-Western country.

Chinese economic reform initiated in 1979 has provided a unique opportunity to examine the impact of institutional transformation on social stratification since it has introduced the principles of the market economy into many spheres of Chinese society (e.g., Bian \& Logan, 1996; Nee, 1989, 1991, 1996; Xie \& Hannum, 1996). One of the most distinct features of Chinese economic reform is that it has taken on a regional dimension, and consequently the extent of market reforms varies by regions (Nee, 1991; Nee \& Mathew 1996; Wang \& Hu, 1999; Xie \& Hannum, 1996; Zhang \&Kanbur, 2005). It provides a basis for conceptualizing market transition with a geographic region. Specifically, some scholars, for instance, utilize economic growth rate of a respondent's residential area to approximate varying levels of market transition and examine how market transition alters social stratification order based on economic resources (Hauser \& Xie 2005; Xie \& Hannum 1996). Along a similar line, Chen (2006) adopts a multilevel analysis and compared the relationship between individual characteristics (e.g., education, experience, and party membership) and elite mobility across Chinese villages with diversifying socioeconomic conditions and institutional environments. Another research utilized the provincial level of privatization as a proxy for marketization and assessed regional variations in psychological distress (Yu, 2008). These 
studies examine different outcomes (i.e., earning, career opportunities, health) at varying levels of Chinese geographical settings (i.e., region, province, city, and village), demonstrating that regional contexts within reform-era Chinese society is of critical importance to understanding social inequality in quality of life among Chinese adults. Nevertheless, extant research has primarily considered regional contexts as a social determinant of health by comparing socioeconomic and health outcomes across regions within China. Therefore, little is known about how regional contexts modify the association between social status and health.

As detailed below, market transition theory and comparison of social stratification in the state-socialist redistributive economy versus market economy suggest that prevailing stratification regimes are contingent upon economic institutions because of dissimilar mechanisms of resource allocation between two - that is, market principle versus political logics (Nee, 1989; Zhou, 2004). Regionally uneven economic reform and institutional variations in stratification process together raise the possibility that Chinese people during the economic reform may not equally convert socioeconomic achievements into favorable health status. Focusing on education and cadre status, this study compares its effect on selfrated health across regions in reform-era China. This research contributes to our understanding of whether and under what conditions social status affects health.

\section{Transition, Regions, and Health Disparities \\ A Cross Regional Comparison on Health Disparities in Reform-era China}

The market transition has been theorized to alter traditional Chinese social hierarchies by replacing political principals with the market as the key mechanisms in resource allocation(e.g., Bian \& Logan, 1996; Nee, 1989, 1991, 1996; Zhou 2000). Meanwhile, research also reveals that influence of political power maintains in China's emerging market economy (Bian \& Logan, 1996; Zhou, 2000). Accordingly, a great deal of empirical research is guided by market transition theory and its analytical focus has been centered on the changing effect of human capital (i.e., education) and political power (i.e., cadre status).

Zhou (2004) differentiates social stratification of industrialized market societies (capitalism) from state-socialist societies (redistributive economy). One of the core characteristics of social stratification in state-socialist societies is a more prominent role of political authority and redistributive power in resource allocation, vis-à-vis capitalist societies. In contrast, social stratification research in the western capitalist society has employed a human capital framework that emphasizes high earning returns to human capital (e.g., education, work experience). Zhou (2004:6) thus suggests that "analytical focus should be on the broader redistributive institutions in understanding social stratification of state-socialist economy while on the individual's market situations in market-economy." Furthermore, Nee (1989: 667) suggested that

“... less market coordination and greater reliance on bureaucratic coordination will result in greater power of the class organized around redistribution. Therefore, in sectors and regions of the socialist economy where allocation and distribution continue to be based upon central decision, there will be little or no chance in the processes determining stratification...we expect more continuity in the distribution of power and privilege in less commercialized hinterland regions..."

Along with regional variations in the progress toward the market economy, the link between stratification and economy institution lends theoretical supports to the cross-regional comparison to the study of social inequalities in reform-era China.

Note that sociological research on market transition has suffered a lack of suitable basis for historical comparison (i.e., pre-reform China) that precludes direct assessment of the extent to which market transition affect stratification (Zhou, Tuma, \& Moen,1997). There are some exceptional studies conducted by Zhou (2000; 2004) who utilizes retrospective data on occupation and earning. Because such type of data is very few, scholars alternatively utilize regions as a proxy for marketization because Chinese economic reform has exhibited much regional variation. As mentioned above, Xie and Hannum (1996) exploit the growth of industrial output in a Chinese city for marketization and shows regional variations in income determinants. To examine the role of work- unit system which was established under Chinese state-socialism. ${ }^{1}$ Xie , Qing, and Wu (2009) include city itself as an indicator of market transition. Similarly, a typology of regions, which is grouped based on provinces, is developed to estimate the local context of marketization (Nee, 1996; Nee \& Cao, 1999; Parish \& Ethan, 1996).

Market transition literature suggests that mechanisms generating social inequality may operate differently across regions in Chinese society. Specifically, social stratification system in more marketized regions such as provinces in the eastern coast of China appears to be closer to those in western capitalist societies. Conversely, regions with less marketized regions such as provinces in southwestern or inland of China likely retain the feature of social stratification established under the state-socialism. This is demonstrated in sociological research on gender inequality in earning determinants, showing that mechanisms of wage determinants in the most marketized regions have moved towards similar patterns observed in capitalist societies with an increasing role of human capital, such as education (Shu \& Bian, 2003). Regional contexts have been important to understanding social inequality in reform-era China, however, there is substantially less attention paid to health outcomes.

Turning to the health disparities, this study draws from the central notion of the fundamental causes of health disparities that explain the persistence of socioeconomic health disparities. Fundamental cause theory postulates that higher social status procures more resources such as money, knowledge, prestige, power, and social connections that can be utilized to reduce the risk of disease and achieve better health (Link \& Phelan, 1995). Fundamental cause theory implies that 
health disparities are an inevitable consequence of social stratification because stratification refers to 'differential access to resources, power, autonomy, and status across social groups' (McLeod \& Nonnemaker, 1999:321). The present study further considers different stratification patterns as Zhou (2004:6) states that "social stratification patterns reflect fundamental institutional arrangements of a society." If there are regional variations in the pace and consequences of market economy reform, it is logical to expect that regionally different stratification patterns would be captured in the shape of health disparities.

Recognizing regional heterogeneity in socioeconomic conditions and market economic penetration this study explores whether education and cadre status is similarly or differently associated with self-rated health across multiple local settings in China. The regional dimension of inequality within the Chinese context generally refers to rural/urban, inland/coastal, and provincial gap. Health research has thus focused on either an urban-rural gap (Fang, Chen, \& Rizzo, 2009; Zimmer, Kaneda, \& Spess, 2007; Zimmer, Wen, \&Kaneda, 2010) or regional effect as a distal cause of health on individual health outcomes (Fang, Dong, Xiao, Liu, Feng, \& Wang, 2010; Pei \& Rodriguez 2006), however less is known about regional discrepancies in heath disparities. In this respect, this paper fills the gap in the literature on health disparities in reform-era China.

\section{Education, Cadre status, and Health: Hypotheses}

Socioeconomic status stratifies access to resources that help reduce the experience of disease or early mortality. This is well evident in favorable health outcomes associated with educational attainment, which has been explained with various pathways, such as positive linkage of education to the work and economic conditions and social-psychological resources (Herd, Goesling, \& House, 2007; Mirowsky \& Ross, 2003; Ross \&Wu, 1995).

A positive effect of education on health is also observed among Chinese adults (Chen, Yang, \& Liu, 2010; Elwell-Sutton et al., 2011; Zimmer et al., 2007; 2010). Education as an indicator of human capital plays a significant role in achieving resources such as employment, earnings, and income, which in turn brings with its beneficial heath consequences (Ross $\& W u$ 1996). Market transition literature has shown increased earning returns to education as market economic reform proceeds (Bian \& Logan,1996; Bian \&Zhang, 2002; Nee, 1989; Walder, 1989; Zhou, 2000). More interestingly, economic returns to education is more salient in regions where labor and capital markets are more developed in Chinese context (Bian \&Zhang, 2002). These considerations lead to the hypothesis that the association between education and health is stronger in more marketized regions than in less marketized regions.

Social status, generally measured by income, education, and occupation, has been considered as a fundamental cause of health disparities (Link \&Phelan, 1995). However, other social conditions that represent dimensions of social stratification and stratify one's access to resources can also qualify as a fundamental cause. In American Society, racial/ethnic segregation has been coined a fundamental cause of health disparities (Schulz et al. 2002; White \& Borrell, 2011). This implies that some additional types of social conditions beyond measures of SES can be considered in certain society, like China. For example, political credentials such as cadre status may play a role as a fundamental cause of health disparities in the state-socialism.

Following institutional variations in stratification, significance and meaning of specific social standings are expected to be modified by institutional structures. In the Chinese context, many social scientists have shown higher returns and privileges to the cadre and members of the Chinese Communist Party relative to their counterparts (Bian \& Zhang, 2002; Nee, 1989,1991,1996; Rona-Tas, 1994; Walder, 1996) and even emphasized the critical role of cadre status in shaping economic-wellbeing of next generation ( $\mathrm{Li}$, Meng, Shi, \&Wu,2012). In the empirical research of market transition, cadre status has also been conceptualized in terms of redistributive power since Nee (1996:916) stated that, "the growth of market institutions causes a decline in the significance of socialist redistributive power even in the absence of fundamental change in the political order."

Political power has been exercised to allocate resources and has access to resources in Chinese society. Therefore, market transition literature has extensively examined changing earning returns to political power. However, a relatively small number of health disparities research included political factors, if any, and revealed rather mixed findings. Yu (2008) finds a statistically nonsignificant association between Communist party membership and degrees of psychological distress. Along with membership in the Communist Party, a cadre position represents an important form of political power in China. Cadre status refers to an individual who holds an official position of political or administrative leadership. A recent study by Zimmer, Wen and Kaneda (2010) included cadre status to understand SES differentials in functional health status transition among elderly Chinese people, and found a positive effect, although it failed to reach statistical significance. On the other hand, research on mortality showed that cadre had a lower risk of mortality, which also explained the urban and rural gap in health differences because urban residents are more likely to be of cadre status (Zimmer, Kaneda, \& Spess, 2007). Moreover, analyzing data from 1994 The State and Life Changes in Urban China Liang (2008) found that the membership in Communist party was associated with better self-rated health. In China, the membership in Communist party and/or cadre status has been well positioned to acquire better monetary rewards (i.e., earning and employment) and non-monetary benefits (i.e., housing and health services), which may contribute to health outcomes (Liang, 2008; Zimmer et al., 2007). Presumably, these mixed findings can be explained by a lack of data that enables scholars to contextualize the role of political power in acquiring monetary and non-monetary advantages. The present study utilizes regional heterogeneity in the extent of economic reform as a proxy of market transition to examine the linkage among market transition, social stratification, and health disparities. In line with a theoretical argument about the salient role of political power in stratification patterns in state-socialist societies, I propose the hypothesis that the association between cadre status and health is stronger in less marketized regions than in more marketized regions. 


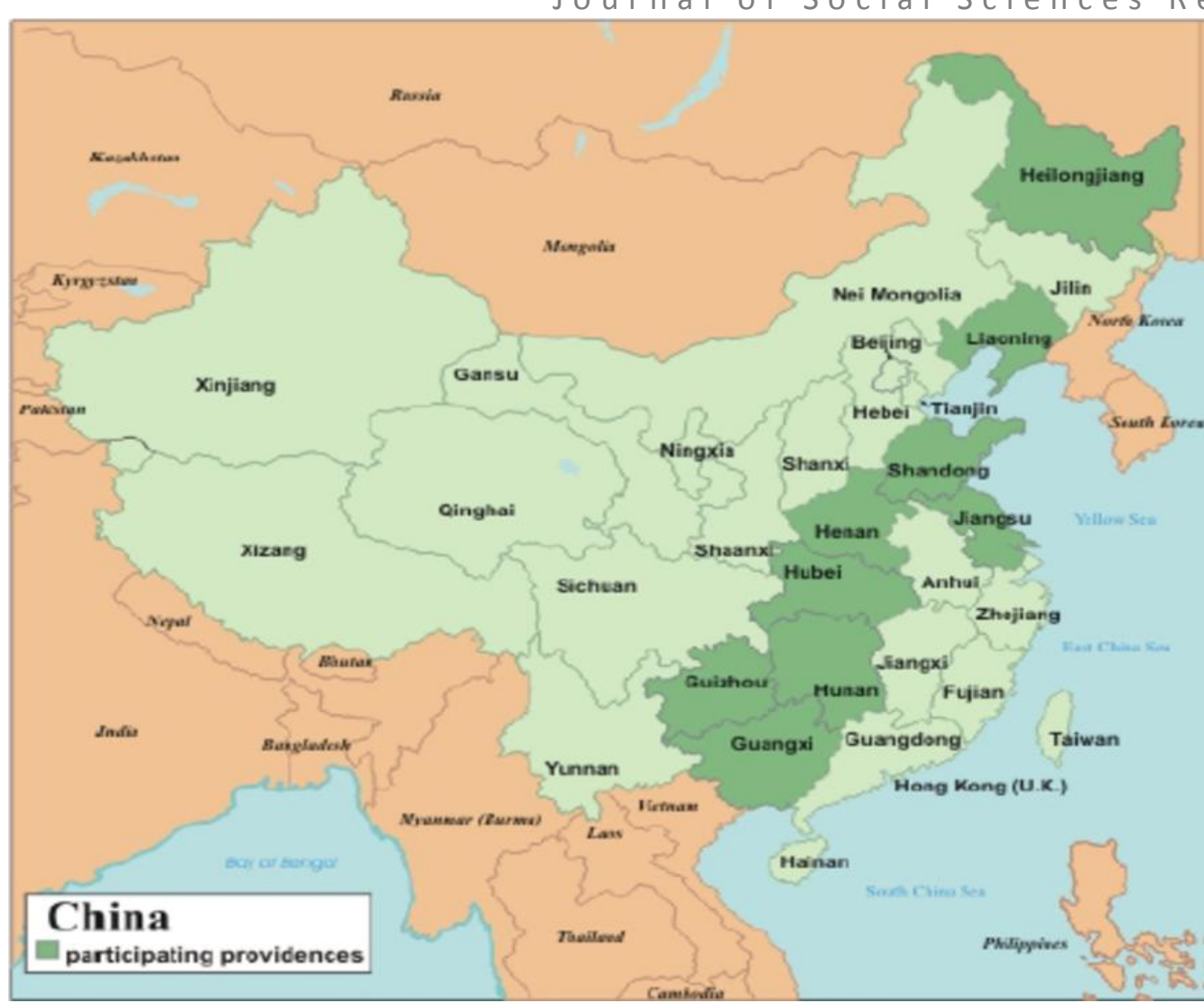

Figure 1. Map of survey provinces for Chinese Health and Nutrition Survey (CHNS)

\section{Methods}

\section{Data}

Data for this study were pooled from an ongoing longitudinal survey, the China Health and Nutrition Survey (CHNS) study that was conducted between 1991 and 2000. The CHNS data were collected using a multistage, random cluster process, and through face-to-face interviews. Counties in the nine provinces were stratified by income (low, middle, and high) and four counties (one in low, two in middle, and one in high-income level) from each province were randomly selected using a weighted sampling scheme. In addition, the research team selected the provincial capital and a lower income city. The provinces covered vary substantially in terms of geography and economic development, thus this dataset is particularly useful for examining regional variations in health disparities (see Figure1). Villages and townships within the counties and urban and suburban neighborhoods within the cities were selected randomly comprising 190 communities (32county capitals, 30 suburban neighborhoods, 32 urban neighborhoods, and 96 villages). Further detailed description of the scope and updates of the survey can be found at http://www.cpc.unc.edu/projects/china. As this study focuses on adults, the sample was restricted to respondents aged 18 years or greater at the time of a given wave's interview. After eliminating cases with missing values, the final sample in this study comprised 7,250 respondents in 1991, 6,597 respondents in $1993,7,779$ respondents in 1997, and 6,601 respondents in 2000; therefore, this study included 28,227 respondents.

\section{Measures}

The outcome of interest in this study was self-rated health, indicating a respondent's health status based on one's own judgment. The variable was assessed using the survey question, "would you say that in general your health is excellent, good, fair, or poor?" The same question was asked in each wave. The variable was coded as 4 for excellent, 3 for good, 2 for fair, and 1for poor. Self-rated health has been proven to be a reliable indicator of general health conditions (Ferraro, Farmer, \&Wybraniec, 1997). 
Journal of Social Sciences Research Table 1. Descriptive Statistics of Variables by Region, Pooled Data from CHNS, 1991-2000

\begin{tabular}{|c|c|c|c|c|c|}
\hline Variables & $\begin{array}{c}\text { Total } \\
(N=28,227)\end{array}$ & $\begin{array}{l}\text { Coastal } \\
(N=6,863)\end{array}$ & $\begin{array}{l}\text { Northeast } \\
(N=4,009)\end{array}$ & $\begin{array}{l}\text { Central } \\
(N=9,678)\end{array}$ & $\begin{array}{l}\text { Southwest } \\
(N=7,677)\end{array}$ \\
\hline \multicolumn{6}{|l|}{ self-rated health } \\
\hline \multirow[t]{2}{*}{ Mean } & 2.82 & 2.95 & 2.93 & 2.78 & 2.71 \\
\hline & $(0.69)$ & $(0.71)$ & $(0.74)$ & $(0.69)$ & $(0.63)$ \\
\hline Poor (\%) & 4.58 & 2.76 & 3.71 & 4.32 & 4.14 \\
\hline Fair (\%) & 26.46 & 19.11 & 20.4 & 24.67 & 26.40 \\
\hline Good(\%) & 55.50 & 57.49 & 54.97 & 59.63 & 63.39 \\
\hline Excellent (\%) & 13.44 & 20.61 & 20.9 & 11.36 & 6.05 \\
\hline \multicolumn{6}{|l|}{ Education } \\
\hline No schooling & 27.89 & 31.06 & 12.64 & 28.31 & 32.51 \\
\hline Primary school & 22.78 & 19.78 & 25.84 & 22.64 & 24.03 \\
\hline Junior high school & 30.23 & 30.9 & 34.22 & 28.50 & 29.73 \\
\hline$\geq$ Senior high school & 19.08 & 18.24 & 27.28 & 20.53 & 13.71 \\
\hline \multicolumn{6}{|l|}{ Politlical power } \\
\hline Cadre status & 6.00 & 5.90 & 8.18 & 6.50 & 4.31 \\
\hline \multicolumn{6}{|l|}{ Regions } \\
\hline Costal & 24.31 & & & & \\
\hline Northeast & 14.20 & & & & \\
\hline Central & 34.28 & & & & \\
\hline Southwest & 27.19 & & & & \\
\hline \multirow[t]{2}{*}{ Age (years) } & 41.85 & 42.54 & 39.7 & 41.68 & 42.58 \\
\hline & $(14.14)$ & $(14.37)$ & (12.39) & 13.81) & $(15.04)$ \\
\hline Gender(female) & 50.46 & 50.40 & 49.48 & 50.17 & 51.40 \\
\hline Marital (being married) & 81.69 & 81.94 & 88.22 & 82.58 & 76.91 \\
\hline \multicolumn{6}{|l|}{ Household Income } \\
\hline \multirow[t]{2}{*}{ Mean } & 3650.25 & 4516.53 & 4106.6 & 3365.75 & 2996.17 \\
\hline & (3411.284) & $(4107.88)$ & (3772.92) & $(3084.69)$ & $(2639.57)$ \\
\hline $1^{\text {st }}$ quartile (\%) & 30.07 & 21.8 & 22.52 & 33.30 & 37.36 \\
\hline $2^{\text {nd }}$ quartile (\%) & 29.28 & 24.06 & 30.88 & 30.35 & 31.78 \\
\hline $3^{\text {rd }}$ quartile $(\%)$ & 25.64 & 30.53 & 28.93 & 23.52 & 31.78 \\
\hline $4^{\text {th }}$ quartile (\%) & 14.98 & 23.62 & 17.66 & 12.83 & 22.26 \\
\hline Currently working & 86.41 & 81.91 & 87.62 & 86.24 & 89.99 \\
\hline Urban residence & 30.19 & 29.46 & 31.27 & 31.59 & 28.51 \\
\hline Farmer & 50.05 & 37.63 & 44.49 & 54.90 & 57.92 \\
\hline Insured & 29.65 & 48.52 & 31.62 & 23.83 & 19.09 \\
\hline Current smoker & 33.58 & 31.85 & 35.76 & 33.50 & 34.10 \\
\hline Alcohol consumption & 37.94 & 37.4 & 40.33 & 36.86 & 38.55 \\
\hline
\end{tabular}


Table 2 presents an overview of the variation in the socioeconomic conditions and health care services. While northeast and central regions were shown to be somewhat indistinguishable in terms of socioeconomic conditions, statistics clearly showed that the coastal region containing Jiangsu and Shangdong province appeared to be the most marketized while the southwestern region containing Guangxi and Guizhou province appear to be the least marketized among the four regions. The National Economic Research Institute (NERI) developed the standardized marketization index for China's provinces, indicating the relative position in the progress towards market economy compared to other provinces (Fan \&Wang, 2001). These statistics are also consistent with a widely recognized coastal-inland gap in terms of various dimensions of socioeconomic conditions.

Table 2. Socioeconomic Development and Infrastructure of Health Services by Regions in Selected Years

\begin{tabular}{|c|c|c|c|c|c|c|c|c|c|c|}
\hline \multicolumn{2}{|c|}{ Year } & \multicolumn{4}{|c|}{1995} & \multicolumn{5}{|c|}{2000} \\
\hline Region & Provinces & $\mathrm{GDP}^{\mathrm{a}}$ & $\begin{array}{c}\text { Private } \\
\text { Employment }\end{array}$ & Education. & $\begin{array}{l}\text { Health } \\
\text { Inst. }\end{array}$ & GDPa & $\begin{array}{c}\text { Private } \\
\text { Employment }\end{array}$ & Education & $\begin{array}{l}\text { Health } \\
\text { Inst. }\end{array}$ & $\begin{array}{c}\text { NERI Index } \\
\text { of } \\
\text { Marketization }\end{array}$ \\
\hline \multirow{2}{*}{ Costal } & Jiangsu & 2136.02 & 50.1 & 59470 & 12039 & 8582.73 & 234.3 & 75643 & 12813 & 6.611 \\
\hline & Shandong & 2196.53 & 73.7 & 52083 & 10463 & 8542.44 & 214.1 & 58355 & 17118 & 5.355 \\
\hline \multirow{2}{*}{ Northeastem } & Liaoning & 1472.95 & 50.8 & 44072 & 6719 & 4669.06 & 124.9 & 53353 & 12564 & 4.956 \\
\hline & Heilongiiang & 864.04 & 19.3 & 30622 & 7637 & 3253 & 53.7 & 35180 & 8038 & 3.472 \\
\hline \multirow{3}{*}{ Central } & Henan & 1279.75 & 31.5 & 37601 & 7661 & 5137.66 & 57.0 & 45709 & 10764 & 3.986 \\
\hline & Hubei & 1088.39 & 42.0 & 41675 & 9774 & 4276.32 & 79.6 & 56566 & 11065 & 3.892 \\
\hline & Hunan & 997.7 & 34.1 & 32931 & $7661 \mid$ & 3691.88 & 46.2 & 47426 & 24678 & 3.703 \\
\hline \multirow{2}{*}{ Southwestem } & Guangxi & 646.6 & 16.0 & 17784 & 5571 & 993.53 & 30.6 & 21858 & 13707 & 3.854 \\
\hline & Guizhou & 339.91 & 12.4 & 8975 & 3934 & 993.53 & 25.6 & 13739 & 8992 & 2.954 \\
\hline
\end{tabular}

Notes: ${ }^{a} 100$ million yuan (1992 year); ${ }^{b} 10,000$ persons

GDP: Gross Domestic Product; Private Employment.: Employees in private enterprises; Education:: \# of graduates institutions of higher

education per 10,000 persons; Health Inst.: \# of health institutions

Sources: China Statistical Yearbook $(1993,1996$, and 2001).

NERI (National Economic Research Institute) Index of Marketization for China's Provinces (Fan and Wang 2001).

Note that NERI is available since 2000 because this index was initially developed in 2000 .

\section{Analysis}

Considering the ordinal nature of the outcome variable, self-rated health, and longitudinal data structure, a mixed-effects ordinal logistic regression model was performed to account for longitudinal dependence with a respondent-specific random intercept. I first examined health differences by education and cadre status as well as provincial variations in health, controlling only for socio-demographic characteristics, such as age and gender along with survey time (Table 3, Model1). Then Model 2 included interactions of regions with education and with cadre status, adjusting socio-demographic characteristics. Finally, Model 3 as a full model controls for other variables, such as components of socioeconomic status (e.g., household income, employment status), health risk behavior (e.g., smoking, alcohol consumption), and time (e.g., survey year). In all models, the southwestern region including Guizhou and Guangxi province was set as the reference category, as they represent the least developed provinces on economic growth and market economic reform (see also Table 2). All statistical analyses were performed using Stata version 12.0 (StataCorp 2011).

\section{Results}

Table 3 presents the results of multivariate analyses of self-rated health. Model 1 contains key covariates, regions, education, and cadre status, adjusting for socio-demographic characteristics (age, gender and marital status). The results from Model 1 that does not include any interaction term shows health differentials by education and cadre status, showing that the highly educated reports better self-rated health compared to individuals without any formal education. In addition, cadre status is also positively associated with self-rated health. Another notable finding from Model 1 is that there are also regional disparities in self-rated health, indicating that residents in more marketized regions are more likely to report better self-rated health compared to those in less marketized regions. The largest regional differences in self-rated health are observed between the coastal and southwestern region $(\mathrm{OR}=2.288, \mathrm{p}<.001)$. This finding suggests that region influences resident's health status and is a significant dimension of health disparities in reform-era China. 
Table 3. Ordinal Logit Mixed Effect Regression of Self-rated Health on Region, Education, and Cadre status Pooled data from CHNS, 1991-2000

\begin{tabular}{|c|c|c|c|c|c|c|c|c|c|}
\hline & \multicolumn{3}{|c|}{ Model 1} & \multicolumn{3}{|c|}{ Model 2} & \multicolumn{3}{|c|}{ Model 3} \\
\hline \multicolumn{10}{|l|}{ Education } \\
\hline \multicolumn{10}{|l|}{ No schooling(ref.) } \\
\hline Primary school & $1.138 * *$ & {$[1.045$} & $-1.239]$ & 1.011 & {$[0.873$} & $-1.171]$ & 0.996 & {$[0.860$} & $-1.153]$ \\
\hline$\geq$ Senior high school & $1.315 * * *$ & {$[1.194$} & - 1.449] & 0.950 & {$[0.793$} & - 1.139] & 0.883 & {$[0.733$} & $-1.065]$ \\
\hline Cadre status & $1.228 * *$ & {$[1.092$} & $-1.382]$ & $1.266 \dagger$ & {$[0.977$} & $-1.640]$ & $1.253 \dagger$ & {$[0.966$} & $-1.625]$ \\
\hline \multicolumn{10}{|l|}{ Region } \\
\hline Coastal & $2.288 * * *$ & {$[2.109$} & $-2.481]$ & $1.774 * * *$ & {$[1.538$} & $-2.046]$ & $1.876 * * *$ & {$[1.624$} & $-2.167]$ \\
\hline \multicolumn{10}{|l|}{ Southwestern(ref.) } \\
\hline \multicolumn{10}{|l|}{ Interactions } \\
\hline Coastal $\times$ primary & & & & $1.361 * *$ & {$[1.091$} & - 1.697] & $1.336 *$ & {$[1.072$} & - 1.666] \\
\hline Coastal $\times$ junior high & & & & $1.392 * *$ & {$[1.138$} & $-1.703]$ & $1.370 * *$ & {$[1.120$} & $-1.675]$ \\
\hline Costal $x \geq$ Senior high school & & & & $1.777 * * *$ & {$[1.387$} & $-2.276]$ & $1.722 * * *$ & {$[1.135$} & $-2.205]$ \\
\hline Northeast $\times$ primary & & & & 1.112 & {$[0.832$} & $-1.486]$ & 1.120 & {$[0.839$} & - 1.497] \\
\hline Northeast $\times$ junior high & & & & $1.358 *$ & {$[1.028$} & $-1.792]$ & $1.361 *$ & {$[1.031$} & $-1.796]$ \\
\hline Northeast $x \geq$ Senior high schoo & & & & $1.440 *$ & {$[1.056$} & $-1.962]$ & $1.397 *$ & {$[1.025$} & $-1.905]$ \\
\hline Northeast $\times$ cadre status & & & & 0.964 & {$[0.666$} & $-1.395]$ & 0.950 & {$[0.656$} & $-1.375]$ \\
\hline Central $\times$ cadre status & & & & 0.998 & {$[0.723$} & $-1.378]$ & 0.980 & {$[0.710$} & $-1.353]$ \\
\hline Log-likelihood & & 7769.377 & & & 27754.55 & & & 27692.193 & \\
\hline
\end{tabular}

Exponentiated coefficients; $95 \%$ confidence intervals in parentheses

tp $<.10 ; * \mathrm{p}<0.05 ; * * \mathrm{p}<0.01 ; * * * \mathrm{p}<0.001$ (two-tailed test)

Notes:Model 1 and Model 2 only control socio-demographic characteristics such as age, gender, and time.

Model 3 controls all other covariates, including age, gender, marital status, household income, smoking, alcohol, insurance status and time.

Results are from the analysis of data pooled across four waves.

Interactions of education and cadre status with region were added to the analysis in Model 2, which is a focal point in this study. Results show that improvement in health status associated with increasing educational attainment is observed more prominently among residents in the coastal region, northeastern region, and central region than in the southwestern region (reference), as indicated by positive and significant interaction terms. The largest odds ratios of interaction with each level of education are observed among residents in the coastal region particularly those with the highest educational attainment, senior high school graduates or above (OR=1.777, $\mathrm{p}<.001)$. A statistically nonsignificant main effect of education in Model 2 indicates that education does not contribute to the shape of health disparities in the southwestern region. The main effect of cadre status in Model 2 suggests that cadre status is positively associated with favorable health (OR $=1.266$, $\mathrm{p}<.10)$. However, it does not much matter to residents in other developed regions as indicated by less than 1 odds ratios for the interaction between cadres and regions, albeit statistically nonsignificant.

Finally, Model 3 consists of the full model, showing consistent results with preceding models while controlling for other SES variables and behavioral risk factors. For example, the effect of senior high school or higher educational attainment on self-rated health in the coastal region is 72 percent higher than in the southwestern region. More specifically, in the coastal region, a senior high school graduates has 52 percent $([0.883 \times 1.722]-1)$ higher odds of reporting favorable health status than those with no formal education. Meanwhile, there is no health benefit associated with education in the southwestern region. Figure 2 depicts differential likelihood of reporting 'excellent' self-rated health by regions and education. As shown in Figure 2, educational gradients in health are most prominent in the coastal region whereas they are least observed in the southwestern region. For example, for the residents in the coastal region, the probability of reporting excellent health 0.112 for individuals with no formal education and 0.261 for those with senior high school or 
higher education in the coastal region; however, such differences are much less pronounced in the southwestern region with .068 for those with no formal education versus 0.112 for those with senior high school or higher education. consistent with the findings on the regional gap in health status, there is regional disparities in self-rated health status that exist at each educational level. Compared to other regions, residents of the coastal region consistently report more favorable health among residents with same educational attainment.

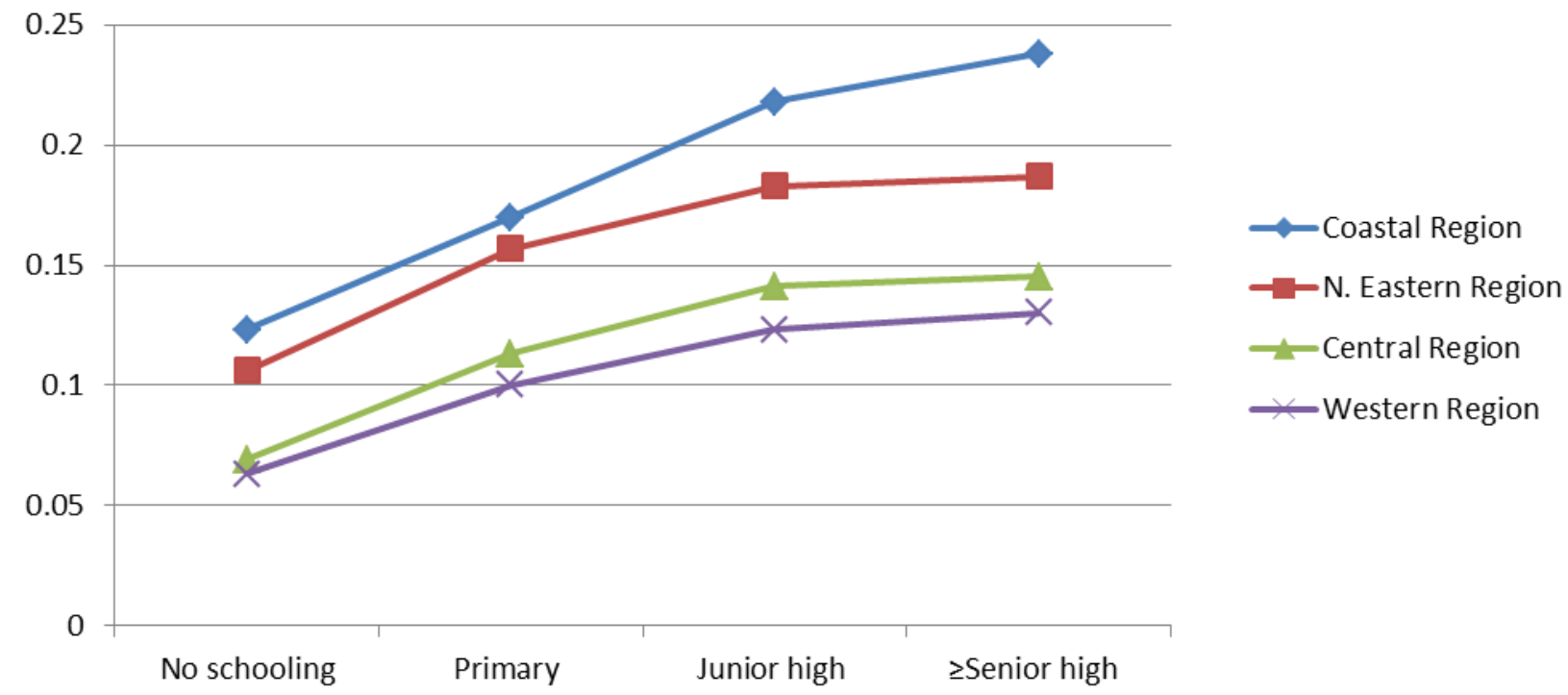

Figure 2. Predicted Probability of 'Excellent' Self-rated Health by Education and Region.

Note: Predicted probabilities were calculated on the basis of Model 3, Table 3.

\section{Discussion \& Conclusion}

Recognizing regional variation in the extent of market economic reform in China, the present study examines the linkage among market transition, social stratification, and health disparities by estimating the interaction effects of education and cadre status with regions. The results reveal that the association between education and self-rated health is most prominent in the coastal region, confirming the first hypothesis. From the perspective of market transition theory and comparative perspective of social stratification, education does not generate advantages for the southwestern region as much as it does for other regions in terms of economic opportunity, career development, and other socioeconomic achievements. This may be due to the lack of market economy institutions and the labor market in the southwestern region (Bell, Khor, \& Kocchhar,1993). One of the most widely accepted explanation for the effect of education is that education affects health via its impact on occupation/employment, income, and wealth (Herd, Goesling, \& House, 2007). As noted earlier, individual's market situation is primarily considered for understanding social stratification of the market economy (Zhou, 2004). A more marketized region is characterized by a competitive labor market in which education exerts significant influence on individual's socioeconomic success and acquiring resources to improve health. This may account for the weaker effect of education in a less marketized region (i.e., southwestern region) and its stronger effects in more marketized regions (i.e., coastal region).

In addition to socioeconomic achievements, education also represents the acquisition and interpretation of health information. It is plausible that poor infrastructure for delivering health care services and facilities in less developed provinces may not allow people with higher education to make full use of their advanced knowledge and (Li \& Wei,2010). Taking an example from Phelan et al.'s study (Phelan, Link, \& Tehranifar, 2010), there is no association between the use of the medical technology and SES before cancer screening developed (see also Link et al., 1998). Along the similar line, even if highly educated individuals residing in the western part of China acknowledge advanced medical technology, health knowledge, and relevant information, they may not be able to gain easy access to and utilize such technology in their residential area with the absence of such facilities and infrastructure. This also implies that the resources which are key to the fundamental cause perspective operate not only at an individual level, but also at a contextual level, as Phelan et al. (2010:s30) pointed out that "... the person benefits in numerous ways that do not depend on his or her own imitative or ability to personally construct a healthy situation; it is an "add-on" benefit operates at the contextual level."

Another possible explanation is a higher quality of educational contents in the most marketized region relative to the least marketized region. To understand the educational gap in health in a contemporary society, it is important to consider the generally improved quality and contents of education because what we learn in school can improve health (Mirowksy \& Ross, 2003). A study showed the significant role of cognitive human capital, which is measured by academic performance, in improving health status (Herd, 2010). Furthermore, high education bears greater knowledge and information about health including transmission of disease and hazard of smoking (Lynch 2003). In this regard, it is possible that quality education with sophisticated contents could be more available at the educational institutions in socio-economically more developed regions. Though there is no systematic study on regional variation in educational quality and specific 


\section{ISSN $2321-1091$ \\ Volume $10 \mathrm{Number} 2$ \\ Journal of Social Sciences Research}

educational contents, people in developed regions tend to enjoy substantial advantages in educational provisions particularly compared to those in many of the impoverished western regions (Hannum \& Wang, 2006; Zhang \& Kanbur, 2005).

Concerning the effect of cadre status, this study finds a positive and marginally significant association between cadre status and favorable self-rated health. In Chinese society, cadre has enjoyed privileges that provide access to health care services (Zimmer et al., 1997), which explain the health benefits associated with a cadre status. In spite of large magnitudes, this positive association is modestly significant $(p<.10)$, which is possibly because of a small number of cadre's cases according to explanation by Zimmer, Wen and Kaneda $(2010)^{2}$. Another finding is that the strength of this association slightly declines in more marketized regions (i.e., coastal, northeastern, and central region) compared to the southwestern region, which does not reach statistical significance. In other words, this study shows that insubstantial differences in the effect of cadre status on self-rated health across regions. According to the market transition thesis, smaller effect of cadre status on health is expected in less marketized regions. While market transition theory and relevant empirical research have focused on economic outcomes such as earning, wealth, and occupational mobility, the present study utilizes self-rated health status as an outcome. Health outcome is associated with not only monetary but also non-monetary benefits. Statistically indiscernible differences in the effect of cadre status on self-rated health across regions at the differing extent of economic reform may indicate that non-monetary benefits, such as health care, housing, and pensions granted to the cadre do not much differ in more marketized regions from those in less marketized regions.

What's more cadre represents a type of occupation with political power such as elite officials, administrators and managerial, usually full time, in government, public organizations and party organization. This implies that psychosocial aspects of cadre's occupational status and its job characteristics including job security, authority, and working conditions may directly or indirectly influence health, which will be immune to change (Mirowksy \& Ross, 2003, 2007; Schieman \&Reid, 2009).

Though not the central focus of this study, the results showed that residents of a more marketized region report better health status, which is consistent with previous studies on regional disparities in health (Fang et al. 2010; Li and Wei 2010; Sun et al. 2011). This finding adds to the evidence that place of residence especially in a society with regionally uneven development has an independent effect on health over and above individual characteristics. From the place of stratification perspective, uneven socioeconomic development across provinces in reform-era China structures access to an array of resources that generate and uphold opportunities to protect the health and avoid risks for disease (Link and Phelan 1995). Given that China Western Development Strategy was launched in 2000 to boost China's less developed western region (xibudakaifa in Chinese) and to reduce regional development discrepancies, future research could examine health consequences of regional development.

This study has limitations, some of which may be addressed in future research. First, the dataset did not cover all provinces in China. By utilizing data from all provinces in China, future research could utilize a multilevel model that allows for province-specific random effect as well as distinct random effects for education and cadre within each province. In so doing, research may be able to estimate to what extent regional variations account for health disparities in reform-era China. Market transition involves changes in various dimensions of socioeconomic structure and sociocultural values including economic growth, a structure of labor market, and organization of work, and social institutions. Among multiple dimensions of changes led by market economic reform, this study did not explicitly specify which conditions account for regional variations in health disparities while the findings were attributed to market economic reform. Finally, I utilized cadre status as a proxy for political power due to the absence of other political variables in the dataset; however future work could explore additional dimensions of political credentials such as party membership.

Despite the limitations outlined above, the findings generated in this study have implications for researchers analyzing a social status and health in general, as well as being interested in the consequences of the market transition to social stratification in individual health in post-socialist societies. The policy implication of current findings suggests that tackling health inequalities in China requires regional context-specific policies.

Note

${ }^{1}$ Work units (danwei in Chinese) refer to a work organization. Under traditional state-socialism, work units have played a substantial role in controlling people's social, economic, and political lives.

${ }^{2}$ They focused on 55 and older Chinese and estimated effect of cadres on mortality and functional limitation. The coefficient of cadre was -0.29 in functional limitation model and -0.60 in mortality model, which were not statistically significant.

\section{REFERENCES}

[1] Beckfield, J. \&N. Krieger (2009). 'Epi + demos + cracy: Linking Political Systems and Priorities to the Magnitude of Health Inequities-Evidence, Gaps, and a Research Agenda. Epidemiologic Reviews, 31,152-77.

[2] Bell, M.W., Khor, Hoe Ee, \& Kochhar, Kalpana. (1993). China at the Threshold of a Market Economy. International Monetary Fund: Washington, DC.

[3] Bian, Y. \& J. Logan (1996). Market Transition and Income Inequality in Urban China. American Sociological Review, 61,759-78. 
[4] Bian, Y, \& Z. Zhang (2002). Marketization and Income in Urban China, 1988 and 1995. Research in Social Stratification and Mobility, 19,377-405.

[5] Chen, J (2006).Elite Mobility in Post-Reform Rural China..Issues \& Studies. 42,43-83

[6] China Statistics Press. (1993). China Statistical Yearbook. Beijing, China: National Bureau of Statistics in China.

[7] China Statistics Press. (1996). China Statistical Yearbook. Beijing, China: National Bureau of Statistics in China.

[8] China Statistics Press (2001). China Statistical Yearbook. Beijing, China: National Bureau of Statistics in China.

[9] Dow,H. \& D. Rehkopf (2010)..Socioeconomic Gradients in Health in International and Historical Context. Annals of the New York Academy of Sciences. 1186,24-36.

[10] Elwell-Sutton, T., C. Jiang, W. Zhang, K. Cheng, T.Lam, G. Leung \& C. Schooling (2011). ,Socioeconomic Influences at Different Life Stages on Health in Guangzhou, China. Social Science \&Medicine. 72(11),1884-92.

[11] Fang, P., S. Dong, J. Xiao, C. Liu, X. Feng, \& Y. Wang (2010) .Regional Inequality in Health and its Determinants: Evidence from China. Health Policy, 94,14-25

[12] Fan, G. \& X. Wang (2001). NERI Index of Marketization of China's Provinces. Economic Science Press (In Chinese).

[13] Ferraro, K., M. Farmer \& J. Wybraniec (1997). Health Trajectories: Long term Dynamics among Black and White Adults. Journal of Health and Social Behavior, 38,38-54.

[14] Hannum, E. \& M. Wang (2006). Geography and Educational Inequality in China',China Economic Review. 17.253-65.

[15] Hauser, S. \& Y. Xie (2005). Temporal and Regional Variation in Earnings Inequality: Urban China in Transition between 1988 and 1995. Social Science Research, 34,44-79.

[16] Herd, P. (2010). Education and Health in Late-life among High School Graduates: Cognitive versus Psychological Aspects of Human Capital. Journal of Health and Social Behavior. 51.478-96.

[17] Herd, P., B. Goesling \& J. House (2007). Unpacking the Relationship between Socioeconomic Position and Health. Journal of Health and Social Behavior, 48,223-38.

[18] Kumanyika S. (2012). Health Disparities Research in Global Perspective: New Insights and New Directions. Annual Review of Public Health, 33:1-5.

[19] Li,Y. \& D. Wei. (2010). A Spatial-temporal Analysis of Healthy Care and Mortality Inequalities in China. Euraisan Geography and Economics .51(6),767-87.

[20] Li,H., L. Meng, X. Shi \& B. Wu (2012). Does Having a Cadre Parent Pay? Evidence from the First Job Offers of Chinese College Graduates. Journal of Development Economics, 99(2),513-20.

[21] Liang, K. (2008), 'Health disparities under market transition: Evidence from nine provinces in China, 1991-2004', PhD dissertation, Department of Sociology, University of Pennsylvania.

[22] Link, B., and J. Phelan (1995).Social Conditions as Fundamental Causes of Disease. Journal of Health and Social Behavior (extra issue),80-94.

[23] Lynch, M. (2003). Cohort and Life-course Patterns in the Relationship between Education and Health: A Hierarchical Approach. Demography, 40(2), 309-31.

[24] McLeod, D.\&J.Nonnemaker (1999). Social Stratification and Inequality Pp 321-44 in Handbook of the Sociology of Mental Health, edited by Aneshensel Carol S., Phelan Jo C. New York: Kluwer.

[25] Mirowsky, J \& C. Ross (2003). Social Causes of Psychological Distress. 2d ed.Hawthorne, New York: Aldine de Gruyter.

[26] Nee, V. (1989). A Theory of Market Transition: From Redistribution to Market in State Socialism. American Sociological Review, 54,663-81.

[27] _ (1991). Social Inequalities in Reforming State Socialism: Between Redistribution and Markets in State Socialism. American Sociological Review, 56,267-82.

[28] — (1996). The Emergence of a Market Economy: Changing Mechanisms of Stratification in China. American Journal of Sociology, 101,908-49.

[29] Nee, V. \& R. Mathews (1996). Market Transition and Societal Transformation in Reforming State Socialism. Annual Review of Sociology, 22,401-35.

[30] Nee, V.\& Y. Cao (1999). Path Dependent Societal Transformation: Stratification in Hybrid Mixed Economies. Theory and Society, 28,799-834.

[31] Olafsdottir, S. (2007).Fundamental Causes of Health Disparities: Stratification, the Welfare State, and Health in the United States and Iceland. Journal of Health and Social Behavior, 48:239-53. 
[32] Parish, W. \&E. Michelson (1996). Politics and Markets: Dual Transformations. American Journal of Sociology, 101, 1042-59.

[33] Pei, X. \& E. Rodriguez (2006). Provincial Income Inequality and Self-reported Health Status in China during 19911997. Journal of Epidemiology and Community Health, 60,1065-69.

[34] Phelan J., B. Link \& P. Tehranifar (2010). Social Conditions as Fundamental Causes of Health Inequalities: Theory, Evidence, and Policy implications. Journal of Health Social Behavior,51 Suppl. S28-40.

[35] Prus, G (2011). Comparing Social Determinants of Self-rated Health across the United States and Canada. Social Science \& Medicine 73,(1),50-9.

[36] Rona-Tas, A. (1994). The First shall be the Last? Entrepreneurship and Communist Cadres in the Transition from State Socialism. American Journal of Sociology, 100,40-9.

[37] Ross, C., \& C-L. Wu (1995). The Links between Education and Health. American Sociological Review, 60(5),719-45.

[38] Ross, C. \& C-L. Wu (1996). Education, Age, and the Cumulative Advantage of Health. Journal of Health and Social Behavior 37(1),104-20.

[39] Schieman, S. \& S. Reid (2009). Job Authority and Health: Unraveling the Competing Suppression and Explanatory Influences. Social Science \& Medicine, 69,1616-24

[40] Schulz, J., D.Williams, B.Israel \& L.Lempert (2002). Racial and Spatial Relations as Fundamental Determinants of Health in Detroit. Milbank Quarterly, 80(4),677-707.

[41] Shu, X. and Y. Bian (2003).Market Transition and Gender Gap in Earnings in Urban China.Social Forces, 81(4),110745.

[42] StataCorp. (2011). Stata Statistical Software: Release 12. College Station, TX: StataCorp LP.

[43] Sun S., J Chen, M. Johannesson, P. Kind, L. Xue, Y. Zhang \& K. Burstom (2011). Regional Differences in Health status in China: Population Health-related Quality of Life Results from the National Health Services Survey 2008. Health and Place, 671-80.

[44] White, K. \& L. N. Borrell (2011). Racial/ethnic Residential Segregation: Framing the Context of Health Risk and Health Disparities. Health and Place, 17,438-48.

[45] Williams, D. \&C. Collins (1995).U.S Socioeconomic and Racial Differences in Health: Patterns and Explanations. Annual Review of Sociology, 21,349-86.

[46] Wang, S. \& A. Hu (1999).The Political Economy of Uneven Development :The Case of China. Armonk, NY:M.E. Sharpe.

[47] Xie, Y. \& E. Hannum (1996). Regional Variation in Earnings Inequality in Reform-Era Urban China. American Journal of Sociology, 101,950-92.

[48] Xie, Y., Q.Lai \&X. Wu (2009). Danwei and Social inequality in Contemporary Urban China. Research in Sociology of Work, 19,283-308.

[49] Yu, W-H. (2008).The Psychological Cost of Market Transition: Mental Health Disparities in Reform-Era China. Social Problems, 55,347-69.

[50] Zhang, X. and R. Kanbur, 2005. Spatial Inequality in Education and Health Care in China. China Economic Review, $16,189-204$

[51] Zhou, X. (2000).Economic Transformation and Income Inequality in Urban China: Evidence from Panel Data. American Journal of Sociology, 105, 1135-74.

[52] _. (2004). The State and the Life Chances in Urban China: Redistribution and Stratification, 1949-1994.

Cambridge: Cambridge University Press.

[53] Zhou, X., N. Tuma \& P.Moen (1997).Institutional Change and Job-Shift Patterns in Urban China, 1949 to 1994. American Sociological Review. 62(3), 339-65.

[54] Zimmer, Z., T. Kaneda \& L. Spess (2007). An Examination of Urban Versus Rural Mortality in China Using Community and Individual Data. Journal of Gerontology: Social Sciences, 62B(5),S349-57.

[55] Zimmer, Z., M. Wen \& T. Kaneda (2010). A Multi-level Analysis of urban/rural and Socioeconomic Differences in Functional Status Transition among Older Chinese. Social Science \& Medicine, 71,559-67. Fröhlich, B. and Plate, J. 2000. The cubic mouse: a new device for three-dimensional input. In Proceedings of the SIGCHI Conference on Human Factors in Computing Systems 